\title{
THE COMPLEX CONTROLLER APPLIED TO THE INDUCTION MOTOR CONTROL
}

\author{
Alfeu J. Sguarezi Filho and Ernesto Ruppert \\ DSCE-FEEC-UNICAMP CEP 13083 - 852, Caixa Postal 6101 , Campinas - SP, Brasil \\ sguarezi@dsce.fee.unicamp.br, ruppert@fee.unicamp.br
}

\begin{abstract}
This paper presents a design and tuning method of the complex gain controller, based on the three-phase induction motor mathematical model complex transfer function to be used in induction motor control when the machine operates at low speed which is a problem so far. The complex gain controller was applied in the direct rotor field orientation control method and also on the direct torque control method. It was designed and tuned using the frequency-response function of the closed loop system. The complex gain controller presents low complexity in the induction motor control implementation. Experimental results were carried out for the controller validation.
\end{abstract}

Keywords - Induction Motor Control, Complex gain controller, Complex Transfer Function, Field orientation, Direct torque control.

\section{INTRODUCTION}

The three-phase induction motor dynamics is traditionally represented by differential equations. The space-vector concept [1] is used in the mathematical representation of the induction machine state variables such as voltage, current, and flux.

The concept of complex transfer function derives from the application of the Laplace transform to the differential equations mentioned above in which the complex coefficients are in accordance with the spiral vector theory which has been presented by [2]. The complex transfer function concept of the three-phase induction motor mathematical model and the induction motor root locus were presented in [3]. Other procedures for modeling and simulating the three-phase induction motor dynamics using the complex transfer function concept are also presented in [4].

The induction machine high performance dynamics is achieved by the field orientation control (FOC) [5,6]. The three-phase induction motor field orientation control using the complex transfer function concept to tune the PI controller by using the frequency-response function of the closed-loop complex transfer function of the controlled induction machine was presented in [7]. This strategy has satisfactory current response although stator currents had presented cross-coupling during the induction machine transients. An interesting solution was presented in [8] in which it was designed a stator-current controller using complex form. From this, the current controller structure employing single-complex zeros is synthesized with satisfactory high dynamic performance.

Manuscript received on 02/06/2008. Revised on 09/10/2008 and 13/07/2009. Accepted by recommendation of the Editor Fernando L. M. Antunes.
Some investigations by using deadbeat $[9,10]$, fuzzy [11], internal mode controller [12] and predictive controller [13] have been presented. These strategies have been presenting satisfactory current response although the complex transfer function of induction motor is not used and low-speed tests had not been shown

An alternative for induction motor drive is the direct torque control (DTC), which consists of the direct control of the stator flux $\lambda_{1}$ and of the electromagnetic torque $T_{e}$. DTC controllers generate a stator voltage space vector that allows quick torque response with the smallest variation of the stator flux. The principles of the DTC using histeresis controllers and variable switching frequency have been presented in [14] and [15]. It has disadvantages such as low speed operation [16].

To solve the variable switching frequency problem DTC strategies operating at constant switching frequency can be implemented by means of closed-loop schemes with PI controllers $[17,18]$, deadbeat $[19,20]$, sliding mode [21, 22], predictive [23] and neuro-fuzzy [24] controllers. The controllers calculate the required stator voltage vector, averaged over a sampling period. These strategies have satisfactory flux and torque response although the complex transfer function of induction motor is not used.

To overcome the low speed operation shortcomings, various approaches for FOC and DTC have been reported using indirect flux detection by on-line reactance measurement method [25], adaptive observer [26] and deadbeat control [27, 28]. These strategies aim the induction motor control operation at low speed. In this case, the complex transfer function and the complex gain controller are not used for such strategy.

This work proposes a design and tuning method for a complex gain control method, based on the threephase induction motor mathematical model complex transfer function to be used in induction motor control when the machine operates at low speed which is a problem so far. The complex gain controller was applied on rotor field orientation control and on the direct torque control. It was designed and tuned by frequency-response function of the closed loop system. The complex gain controller presents a minor complexity for the induction motor control implementation when compared to the techniques mentioned above. Experimental results were carried out for the controller validation.

\section{THE COMPLEX MATHEMATICAL MODEL OF THE THREE-PHASE INDUCTION MACHINE}

The induction motor mathematical model is written in the synchronous reference frame $(\mathrm{dq})$ and the state variables are stator current space vector $\vec{i}_{1}$ and stator flux space vector $\vec{\lambda}_{1}$ 


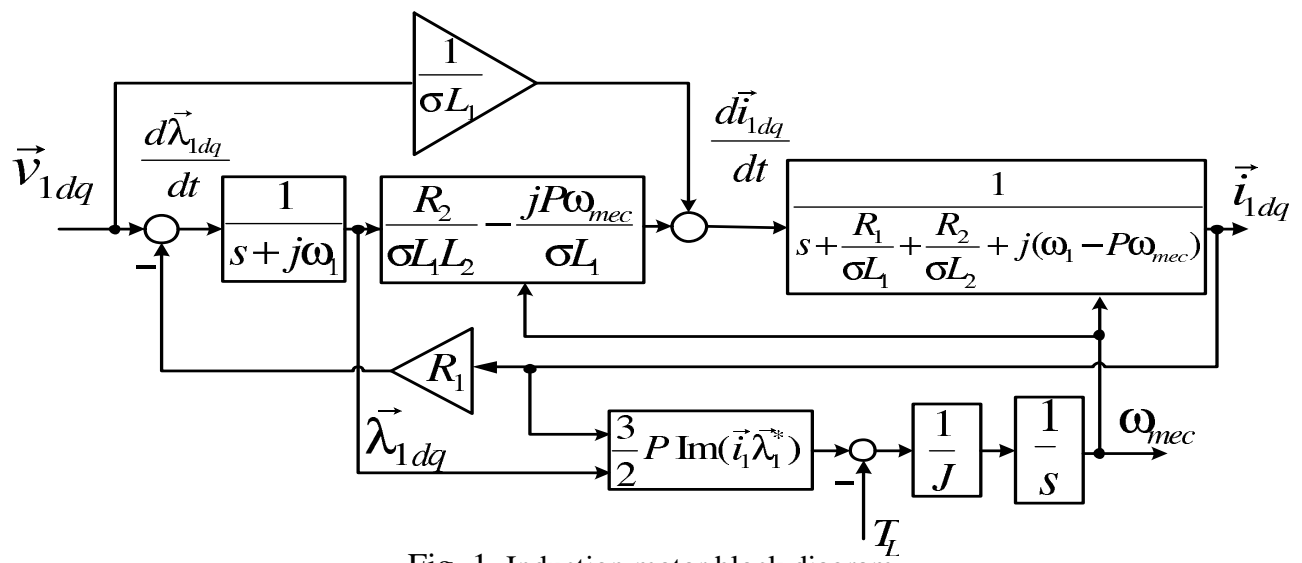

Fig. 1. Induction motor block diagram.

[29].

$$
\left[\begin{array}{l}
\dot{\vec{\lambda}}_{1 d q} \\
\dot{\vec{i}}_{1 d q}
\end{array}\right]=\left[\begin{array}{ll}
a_{1} & a_{2} \\
a_{3} & a_{4}
\end{array}\right]\left[\begin{array}{l}
\lambda_{1 d q} \\
\vec{i}_{1 d q}
\end{array}\right]+\left[\begin{array}{l}
\vec{v}_{1 d q} \\
\frac{\vec{v}_{1 d q}}{\sigma L_{1}}
\end{array}\right]
$$

Where

$$
\begin{gathered}
a_{1}=-j \omega_{1} \\
a_{2}=-R_{1} \\
a_{3}=\left(\frac{R_{2}}{\sigma L_{1} L_{2}}-\frac{j P \omega_{m e c}}{\sigma L_{1}}\right) \\
a_{4}=-\left[\frac{R_{1}}{\sigma L_{1}}+\frac{R_{2}}{\sigma L_{2}}+j\left(\omega_{1}-P \omega_{m e c}\right)\right]
\end{gathered}
$$

and $\sigma$ is the leakage coefficient. The machine mechanical dynamics is given by

$$
J \frac{d \omega_{m e c}}{d t}=\frac{3}{2} P \mathcal{I} m\left(\vec{i}_{1 d q} \vec{\lambda}_{1 d q}^{*}\right)-T_{L}
$$

The subscripts 1,2 and $m$ represent the stator, rotor and magnetization parameters respectively, $\omega_{1}$ is the synchronous speed, $\omega_{m e c}$ is the machine mechanical speed, $R_{1}$ and $R_{2}$ are the per phase estator and rotor windings electrical resistance, respectively, $L_{1}, L_{2}$ and $L_{m}$ are the proper and mutual inductances of the stator and rotor windings, $\vec{v}$ is the voltage vector, $P$ is the machine number of pair of poles, $J$ is the load and rotor inertia moment and $T_{L}$ is the machine load torque.

In order to obtain the induction motor complex transfer function the Laplace transform is applied to (1) in accordance with the complex transfer function concept, it is assumed that the mechanical time constant of the motor is much larger than the transient electromagnetic time constants and the saturation effects is neglected. Thus, $\omega_{m e c}=$ constant is a valid approximation $[2,8,30]$. The induction motor block diagram originated by use of (1) and (6) is shown in Figure 1.

When designing the DFOC or DTC control systems through the induction motor complex transfer function, $\vec{v}_{1 d q}$ is considered as the input and the $\vec{i}_{1 d q}$ is considered as the output. Therefore the induction machine complex transfer function
$H(s)$ is derived from the application of the Laplace transform to the equation (1) and it has the form given in 7.

$$
H(s)=\frac{I_{1 d q}}{V_{1 d q}}=\frac{\left(\frac{s+j \omega_{1}}{\sigma L_{1}}\right)+a_{3}}{\left(s+j \omega_{1}\right)\left(s+a_{4}\right)+R_{1} a_{3}}
$$

Where $I_{1 d q}=\mathcal{L}\left\{\vec{i}_{1 d q}\right\}$ and $V_{1 d q}=\mathcal{L}\left\{\vec{v}_{1 d q}\right\}$.

\section{DIRECT ROTOR FIELD ORIENTATION CONTROL}

The direct rotor field orientation control (DFOC) allows to control the flux magnitude $\lambda_{2}$ and torque $T_{e}$ through the stator currents [6] with the relationship given by

$$
\lambda_{2}=i_{1 d} L_{M}
$$

and

$$
T_{e}=\frac{3 L_{M}}{2 L_{2}} P \lambda_{2} i_{1 q}
$$

Using the complex notation in the direct rotor field orientation strategy where $i_{1 d}$ is the real component and $i_{1 q}$ is the imaginary component of the stator current. Thus, the traditional PI controller presented in [31] can be substituted by the complex gain $(a+j b)$. This controller generates the voltage reference by using the stator current space vector error $\left(\varepsilon_{i_{1 d}}+j \varepsilon_{i_{1 q}}\right)$. The reference voltage space vector is given by

$$
\vec{v}_{1 q_{r e f}}=(a+j b)\left(\varepsilon_{1 d}+j \varepsilon_{1 q}\right)
$$

which means

$$
\begin{aligned}
& v_{1 d_{r e f}}=\left(a \varepsilon_{1 d}-b \varepsilon_{1 q}\right) \\
& v_{1 q_{r e f}}=\left(b \varepsilon_{1 d}+a \varepsilon_{1 q}\right)
\end{aligned}
$$

Where $a$ is the real component of the complex gain, $b$ is the imaginary component of the complex gain, $\varepsilon_{i_{1 d}}$ is the error between $i_{1 d_{r e f}}$ and $i_{1 d}$ and $\varepsilon_{i_{1 q}}$ is the error between $i_{1 q_{r e f}}$ and $i_{1 q}$. The direct rotor field orientation strategy with the complex gain controller is shown in Figure 2. 


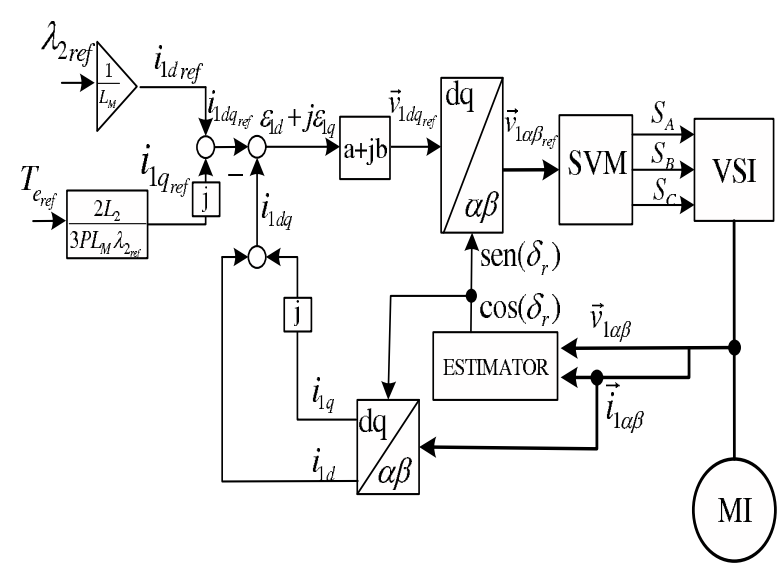

Fig. 2. DFOC strategy with complex gain controller.

The reference stator voltage vector $\vec{v}_{1 d q_{r e f}}$ is transformed by using rotor flux angle $\delta_{r}$ to obtain the stator voltage in the stationary reference frame $\alpha \beta$ as it is shown in the next section.

\section{A. Rotor Flux Estimation}

The stator flux estimation is given by

$$
\vec{\lambda}_{1 \alpha \beta}=\int\left(\vec{v}_{1 \alpha \beta}-R_{1} \vec{i}_{1 \alpha \beta}\right) d t
$$

An interesting flux estimation at low speed using equation (13) is obtained by using the integration method given by [32]. The rotor flux estimation is done by

$$
\vec{\lambda}_{2 \alpha \beta}=\frac{L_{2}}{L_{M}} \vec{\lambda}_{1 \alpha \beta}+\frac{L_{M}^{2}-L_{1} L_{2}}{L_{M}} \vec{i}_{1 \alpha \beta}
$$

Where the subscript $\alpha \beta$ is used to designate the stator stationary reference frame which is being used.

The rotor flux angle is estimated by using the trigonometric transfer function

$$
\delta_{r}=\arctan \left(\frac{\lambda_{2 \beta}}{\lambda_{2 \alpha}}\right)
$$

\section{B. Design of the Complex Gain}

The tuning operation of the complex gain controller requires the transfer function of the closed loop system, to obtain its frequency-response function. In the induction motor complex transfer function (7) $\vec{v}_{1 d q}$ is considered as the input and the $\vec{i}_{1 d q}$ is considered as the output.

The frequency-response function of the $H(s)$ given in (7) is shown in Figure 3. The low speed utilized in this paper is 125 $\mathrm{rpm}(13 \mathrm{rad} / \mathrm{s})$ that corresponds to $4.16 \mathrm{~Hz}$. As the variables at synchronous referential are constants the angle of the current $\vec{i}_{1 d q}$ is neglected.

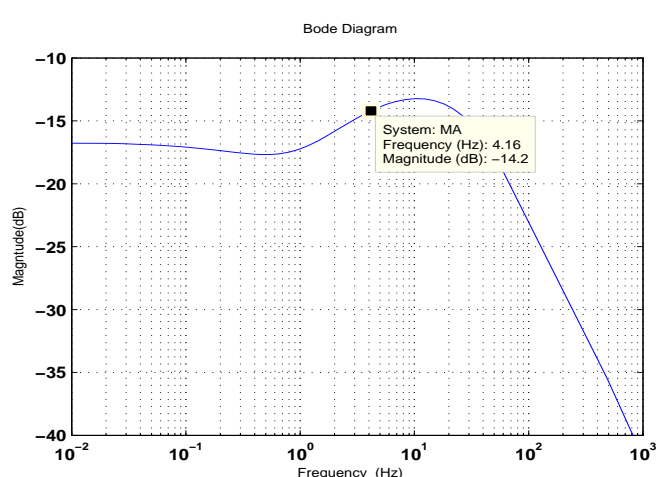

Fig. 3. Induction motor (7) frequency-response function.

In accordance with the control theory $[33,34]$ the control system block diagram used to obtain the closed loop transfer function is presented in Figure 4.

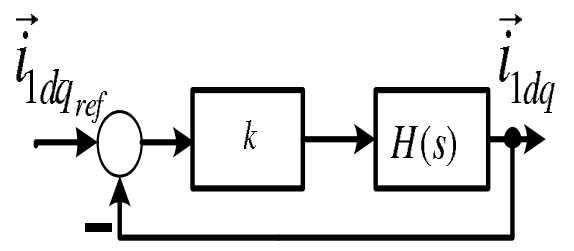

Fig. 4. System to design the complex gain.

Where $k=a+j b$. The transfer function of the system presented in Figure 4 is given by

$$
C(s)=\frac{(a+j b) H(s)}{1+(a+j b) H(s)}
$$

For non-load induction motor it yields

$$
C(s)=\frac{\left[\frac{\left(s+j \omega_{1}\right)}{\sigma L_{1}}+\frac{R_{2}}{\sigma L_{1} L_{2}}-\frac{j P \omega_{m e c}}{\sigma L_{1}}\right](a+j b)}{m(s)-j P \omega_{m e c} \frac{R_{1}}{\sigma L_{1}}+n(s)(a+j b)}
$$

Where

$$
m(s)=\left(s+j \omega_{1}\right)\left(s+\frac{R_{1}}{\sigma L_{1}}+\frac{R_{2}}{\sigma L_{2}}\right)+\frac{R_{1} R_{2}}{\sigma L_{1} L_{2}}
$$

and

$$
n(s)=\left[\frac{\left(s+j \omega_{1}\right)}{\sigma L_{1}}+\frac{R_{2}}{\sigma L_{1} L_{2}}-\frac{j P \omega_{m e c}}{\sigma L_{1}}\right] .
$$

In the case of the $4.16 \mathrm{~Hz}$ the complex gain to achieve $0 \mathrm{~dB}$ magnitude of $\mathrm{H}(\mathrm{s})$ in the equation (17) is $75-25 \mathrm{j}$ as it can be shown in Figure 5. 


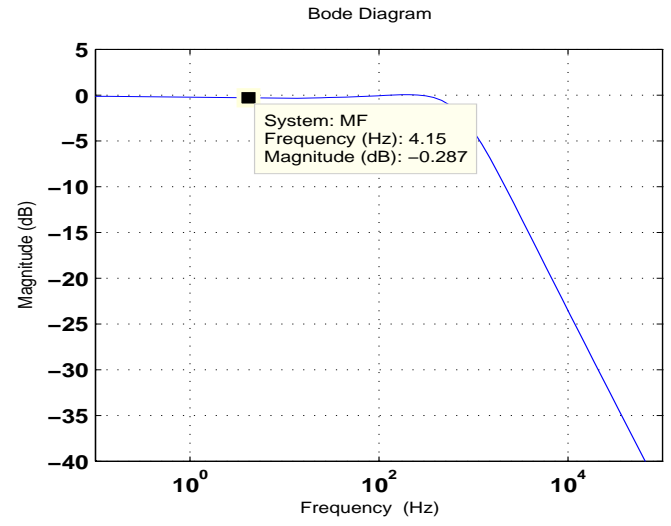

Fig. 5. Frequency-response function of the equation (17).

\section{DIRECT TORQUE CONTROL}

By using stator field orientation in this present work, the torque and stator flux must become parts of a complex number, where the magnitude of the stator flux $\lambda_{1}$ is the real component and the torque $T_{e}$ is the imaginary component. Hence, the reference signals and the error become a complex number. Thus, the traditional PI controller presented in [17] can be substituted by complex gain $(a+j b)$. This gain has the function to generate a voltage reference vector using the stator flux-torque vector error $\left(\varepsilon_{\lambda}+j \varepsilon_{T}\right)$. This way the stator voltage vector in this control strategy is given by

$$
\vec{v}_{1 d q_{r e f}}=\left(\varepsilon_{\lambda}+j \varepsilon_{T}\right)(a+j b)
$$

wich means that the direct and quadrature axis of the voltage vector are

$$
\begin{gathered}
v_{1 d_{\text {ref }}}=\left(-\varepsilon_{T} b+\varepsilon_{\lambda} a\right) \\
v_{1 q_{\text {ref }}}=\left(\varepsilon_{T} a+\varepsilon_{\lambda} b\right)
\end{gathered}
$$

Where $a$ is the real component of complex gain, $b$ is the imaginary component of complex gain, $\varepsilon_{\lambda}$ is the flux error signal and $\varepsilon_{T}$ is the torque error signal.

The block diagram of the strategy with the complex gain is presented in Figure 6.

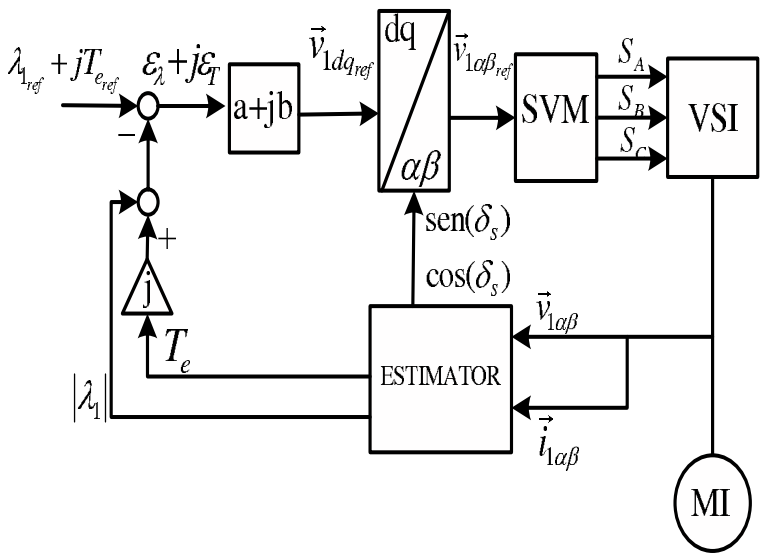

Fig. 6. DTC strategy with complex gain controller.
The reference stator voltage vector $\vec{v}_{1 d q_{r e f}}$ is transformed by using stator flux angle $\delta_{s}$ to obtain the stator voltage at stationary reference frame $\alpha \beta$.

The stator flux estimation is obtained by using equation (13) in section III.A and its angle is estimated by using the trigonometric transfer function

$$
\delta_{s}=\arctan \left(\frac{\lambda_{1 \beta}}{\lambda_{1 \alpha}}\right) .
$$

\section{Design of the Complex Gain}

The tuning operation for the complex gain determination requires the transfer function of the closed loop system to obtain its frequency-response function.

The frequency is chosen in accordance with the the induction motor desired speed operation to design the complex gain.

In accordance with the DTC control strategy the induction motor output has to be the stator flux magnitude $\lambda_{1}$ and the torque $T_{e}$. Therefore the $\mathrm{H}(\mathrm{s})$ outputs have to become the stator flux magnitude $\lambda_{1}$ and the torque $T_{e}$ according equation (7). The expression to obtain the stator flux by using the stator current $i_{1 d}$ is given by

$$
\lambda_{1}=\lambda_{1 d} \cong G \sigma L_{1} i_{1 d}
$$

and to obtain the electromagnetic torque in the $d q$ reference frame one may use the expression:

$$
T_{e}=\frac{3}{2} P \lambda_{1} i_{1 q}
$$

As the stator flux magnitude $\lambda_{1}$ is assumed to be essentially constant, through of the equations (7), (24) and (25) the new transfer function is achieved with torque and flux as output and it is given by

$$
\frac{X_{\lambda T}}{V_{1 d q}}=H(s)\left(G \sigma L_{1}+j P \frac{3}{2} \lambda_{1}\right)
$$

Where $X_{\lambda T}=\mathcal{L}\left\{\lambda_{1}+j T_{e}\right\}$. The frequency-response function of equation (26) is presented in Figure 7 at frequency $4.16 \mathrm{~Hz}$ to tuning the complex gain.

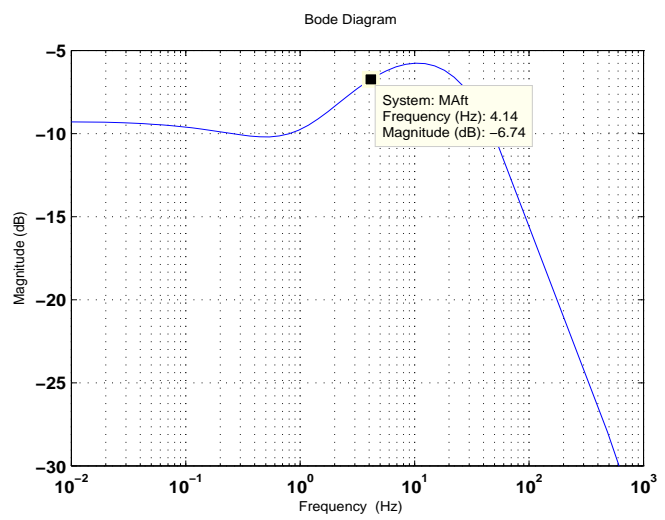

Fig. 7. Frequency-response function of the equation (26). 
Then, from equations (20) and (26) one obtain the control system block diagram and it is presented in Figure 8.

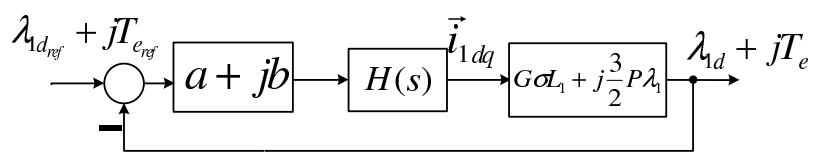

Fig. 8. System to design the complex gain.

The expression of the closed loop transfer function of the control system shown in Figure 8 is given by

$$
\frac{X_{\lambda T}}{X_{\lambda T_{r e f}}}=\frac{(a+j b) H(s)\left(G \sigma L_{1}+j P \frac{3}{2} \lambda_{1}\right)}{1+(a+j b) H(s)\left(G \sigma L_{1}+j P \frac{3}{2} \lambda_{1}\right)}
$$

Where $X_{\lambda T_{\text {ref }}}=\mathcal{L}\left\{\lambda_{1_{\text {ref }}}+j T_{e_{\text {ref }}}\right\}$. At the frequency of $4.16 \mathrm{~Hz}$ the complex gain was calculated by using simulations, considering slip approximately null and the 0 $\mathrm{dB}$ magnitude. Its value is $125-j 25$. The frequencyresponse function of equation (27) is shown in Figure 9 and its magnitude is near $0 \mathrm{~dB}$.

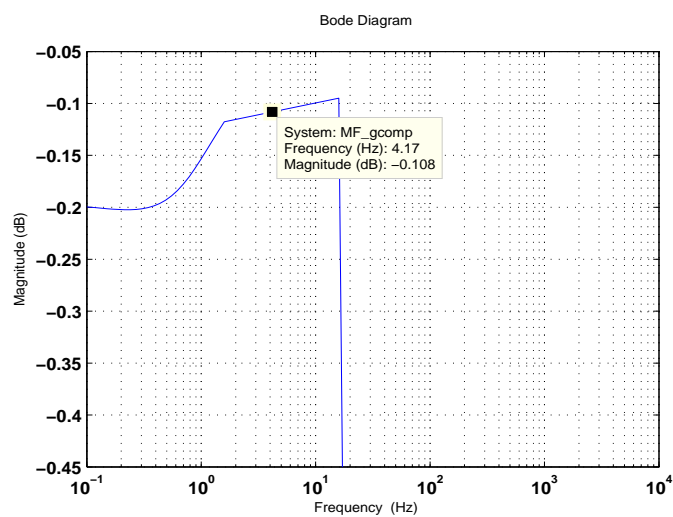

Fig. 9. Frequency-response function of the equation (27).

\section{DIFERENCE BETWEEN FORMULATIONS OF THE COMPLEX GAIN CONTROLLER AND OF THE PI CONTROLLER}

The induction machine stator voltage was computed using the complex gain controller of the equation (10) for DFOC and of the equation (20) for DTC. In both cases the computed stator voltage $v_{1 d q}$ was the result of the product of two complex numbers: the complex error and the complex gain controller.

In the case of the PI controller use, in direct rotor field orientation control, the $v_{1 d q}$ is given by

$$
\begin{aligned}
& v_{1 d_{r e f}}=k_{p 1} \varepsilon_{1 d}+\frac{k_{i 1}}{s} \varepsilon_{1 d} \\
& v_{1 q_{r e f}}=k_{p 2} \varepsilon_{1 q}+\frac{k_{i 2}}{s} \varepsilon_{1 q}
\end{aligned}
$$

for direct torque control the $v_{1 d q}$ is given by

$$
\begin{aligned}
& v_{1 d_{r e f}}=k_{p 1} \varepsilon_{\lambda}+\frac{k_{i 1}}{s} \varepsilon_{\lambda} \\
& v_{1 q_{r e f}}=k_{p 2} \varepsilon_{T}+\frac{k_{i 2}}{s} \varepsilon_{T}
\end{aligned}
$$

Where $k_{p 1}, k_{p 2}, k_{i 1}$ and $k_{i 2}$ are the parameters of the PI controller. It can be seen in equations (28), (29), (30) and (31) that it is necessary one PI controller to compute each stator voltage component. Thus, the parameters of two PI controllers have to be tuned for induction motor control.

Comparing the equations (28) with (11), (30) with (21), (29) with (12) and (31) with (22) it can be seen that $v_{1 d q}$ was computed by a complex product between the complex error vector and the complex gain controller and in the case of the PI controller, each component of the $v_{1 d q}$ was computed by a product between a PI controller and the error of each component. Thus, using the complex gain controller the parameters number of the controller was reduced from four to two. Obviously this reduction decreases the difficult to tune the parameters of the controller.

\section{EXPERIMENTAL RESULTS}

The DFOC and DTC strategies were implemented using a Texas Instruments DSP TMS320F2812 platform. The system consists of a three-phase voltage source inverter with insulated-gate bipolar transistors (IGBTs) and the three-phase induction motor wich electrical and mechanical characteristics are shown in the appendix. The stator voltage commands were modulated by using symmetrical space vector PWM with switching frequency equal to $2.5 \mathrm{kHz}$. The DC bus voltage of the inverter is $226 \mathrm{~V}$ and the stator voltages and currents was sampled in the frequency of $2.5 \mathrm{kHz}$. A conventional PI controller generates a torque reference by using the speed error. The flux and torque estimation, and the flux-torque complex regulator and speed controller have the same sampling frequency of $2.5 \mathrm{kHz}$. The encoder resolution is 1500 pulses per revolution.

Three no-load induction motor tests were made. The first one was the response to a torque step of $12.2 \mathrm{Nm}$ which is shown in Figure 10. The $i_{1 q_{r e f}}$ is calculated by equation (25). The response of the DTC with complex controller presented a slightly better performance during the transient and steady state when such response is compared with the response to the DTC with PI controller and DFOC with complex gain controller although the response of DFOC has less oscillations. These oscillations occur due to the natural lack of accuracy in the measurements of currents and voltages and induction motor parameters variations [35].

In the second test the speed varies in forward and reversal operation and the results are presented in Figure 11. The speed changes from $13 \mathrm{rad} / \mathrm{s}$ to $-13 \mathrm{rad} / \mathrm{s}$ in $1 \mathrm{~s}$ and the complex gain is not changed during the test. This result confirms the satisfactory performance and the robustness of the controller due to the fact that the speed reaches the reference in several conditions. The responses of the DTC and DFOC with complex gain controller and of the DTC with PI controller have similar performance in the transient and in the steady 
state. The small error occurs due to the natural lack of accuracy in the speed measurement.

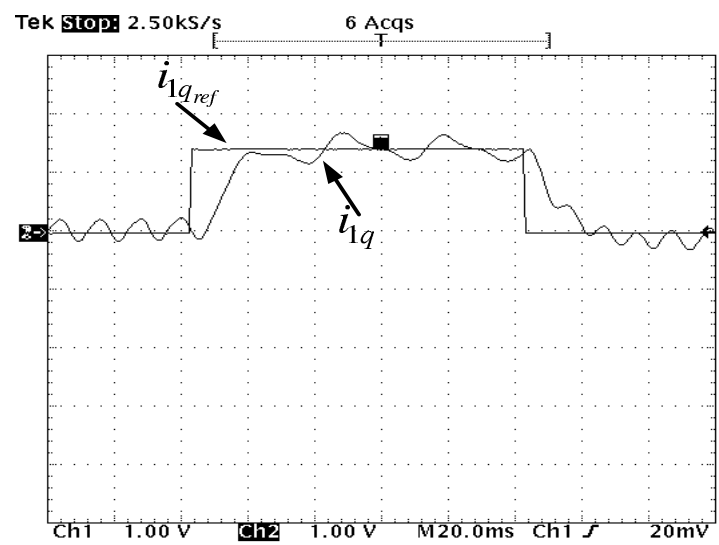

(a) DFOC $-i_{i q_{\text {ref }}}$ step function (4.2 A/div).

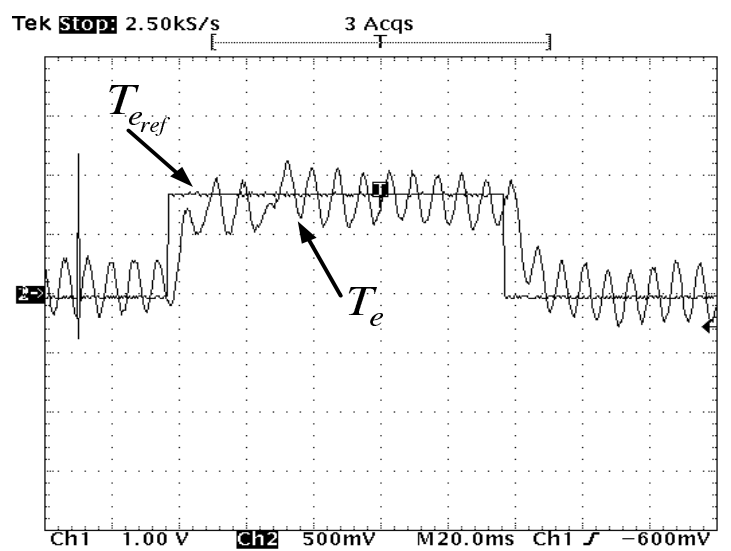

(b) DTC - $T_{e_{\text {ref }}}$ step input function with complex controller (9 Nm/div).

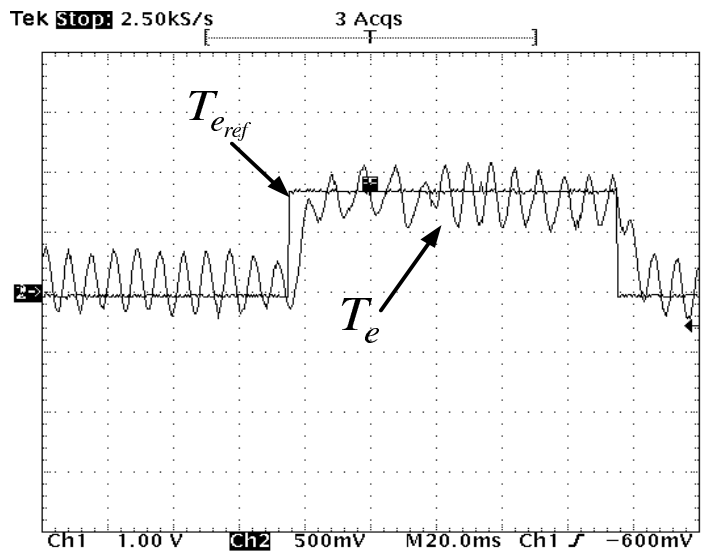

(c) DTC $-T_{e_{r e f}}$ step input function with PI controller (9 $\mathrm{Nm} /$ div).

Fig. 10. Responses to step torque operation.

Figure 12 presents the speed response when the speed varies from $6.28 \mathrm{rad} / \mathrm{s}$ to $-6.28 \mathrm{rad} / \mathrm{s}$. The response of the DTC control with complex gain controller presented a slightly better performance in steady state when such response is compared with the response of DTC with PI controller and DFOC with complex gain controller. The result confirms the satisfactory performance and the robustness of the complex controller again due to the fact that the speed reaches the reference value although the complex gain is designed for induction motor operation at $4.16 \mathrm{~Hz}$.

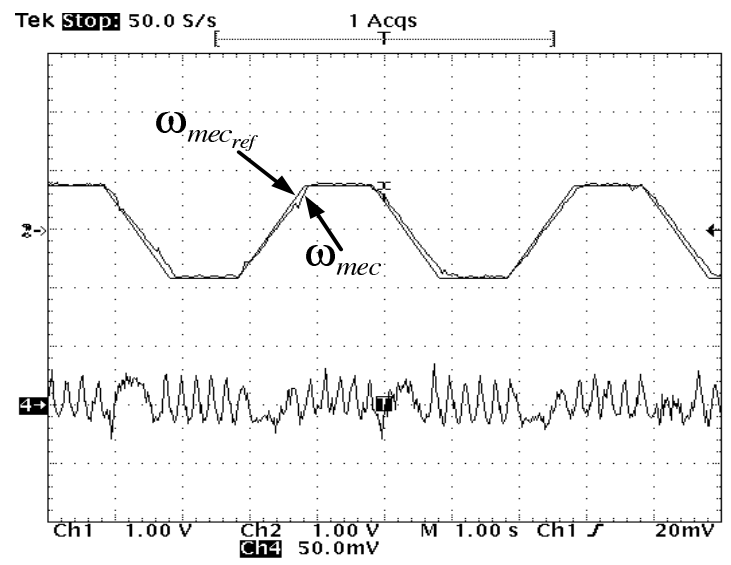

(a) $\mathrm{DFOC}$ - speed (15.3 rad/s.div).

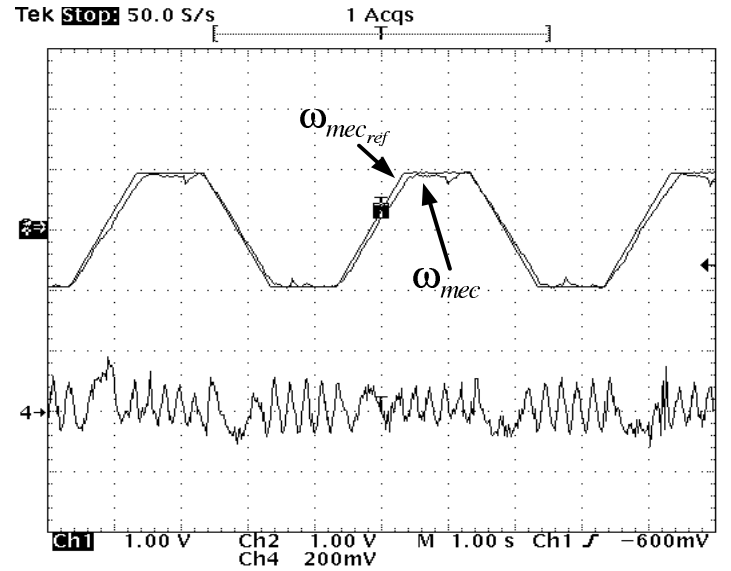

(b) DTC - speed with complex controller (13 rad/s.div).

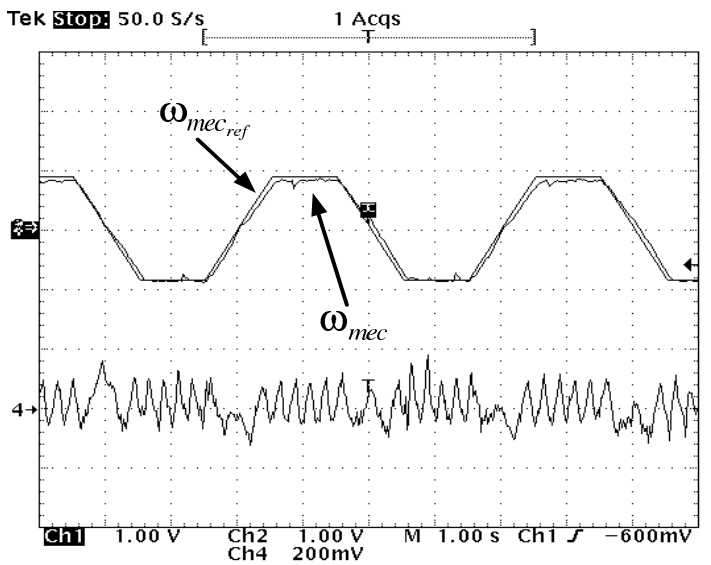

(c) DTC - speed with PI controller (13 rad/s.div).

Fig. 11. Speed forwad and reversal operation and current of phase $a$ (10 A/div). 


\section{CONCLUSION}

The concept of complex transfer function associated with the complex gain controller allows the design and tuning the complex controller by using the closed loop system frequency response function of the controlled induction motor.

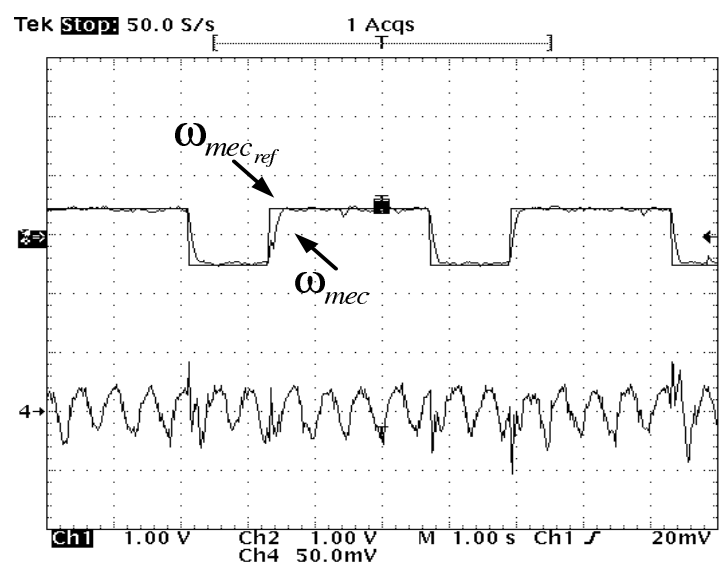

(a) DFOC - speed (12.57 rad/s.div).

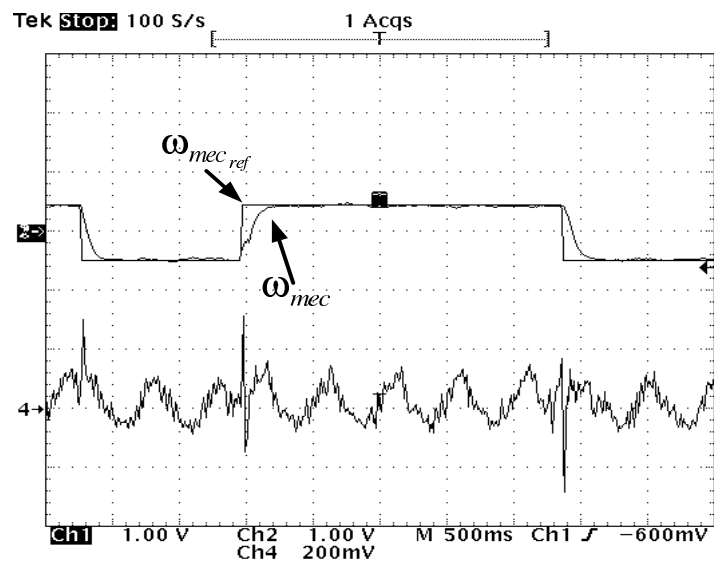

(b) DTC - speed with complex controller (12.57 rad/s.div).

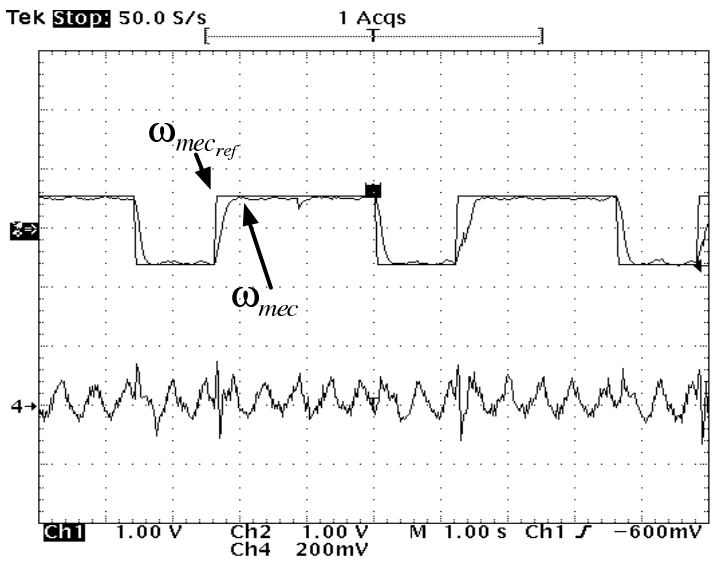

(c) DTC - speed with PI controller (12.57 rad/s.div).

Fig. 12. Speed response to step operation and current of phase $a(6$ A/div).

The experimental results presented the satisfactory performance and the robustness of the complex controller due to the fact that the speed reaches the reference value in several conditions although the complex gain had been designed for induction motor operation at $4.16 \mathrm{~Hz}$. The complex gain controller has presented a slightly better performance in steady state when such response was compared with the response of the DFOC and to the DTC with PI [17] although the DFOC had less oscillation in the torque response [30]. Thus, the design of complex gain has an acceptable robustness although a detailed analysis considering parameters variations and other several speed operations has to be done. Due to the variable speed operation maybe it will be necessary to construct a table with complex gains designed for each speed desired speed or to an each speed range.

The complex gain controller overcomes the low speed operation shortcomings in the rotor flux orientation control and in the direct torque control with a minor complexity solution when compared with the solutions presented by indirect flux detection by on-line reactance measurement method [25], adaptive observer [26] or deadbeat [27].Thus, the complex vector notation and the complex gain controller become an interesting tool for implementation induction motor drives.

\section{APPENDIX}

Three-phase induction motor variables and parameters: $P N=2.3 \mathrm{~kW} ; V_{N}=220 \mathrm{~V} ;$ Poles $=4 R_{1}=2.229$ $\Omega ; R_{2}=1.522 \Omega ; L_{m}=0.238485 \mathrm{H} ; L_{1}=0.2470 \mathrm{H}$; $L_{2}=0.2497 \mathrm{H} ; J=0.0067 \mathrm{Kgm}^{2}$.

\section{REFERENCES}

[1] P. K. Kovács and E. Rácz. Transient Phenomena in Electrical Machines. Amsterdam, The Netherlands: Elsevier, 1984.

[2] S. Yamamura. Spiral Vector Theory of AC Circuits and Machines. Clarendon Press OXFORD, 1992.

[3] J. Holtz. The representation of ac machine dynamics by complex signal flow graphs. IEEE Trans. Ind. Electron., 42:263-271, June 1995.

[4] M. M. Cad and M. L. de Aguiar. The concept of complex transfer functions applied to the modeling of induction motors. IEEE Winter Meeting 2000 of the IEEE Power Engineering Society, 2000.

[5] F. Blaschke. The principle of field orientation control as applied to the new transvector closed loop control system for rotating machines. Siemens Review, 39(5):217-220, March/April 1977.

[6] D. W. Novotny and T. A. Lipo. Vector Control and Dynamics of AC Drives. Clarendon Press OXFORD, 1996.

[7] F. Briz, M. W. Degener, and R. D. Lorenz. Analysis and design of current regulators using complex vectors. IEEE Trans. Ind. Applicat., 32:817-825, May-June 2000.

[8] J. Holtz, J. Quan, J. Pontt, J. Rodríguez, P. Newman, and H. Miranda. Design of fast and robust current regulators for high-power drives based on complex state variables. IEEE Trans. Ind. Applications, 40:1388-1397, September/October 2004.

[9] A. C. Oliveira, A. M. N. Lima, and C. B. Jacobina. 
Controladores digitais de corrente para máquina de indução. Eletrônica de potência, 1(1):43-48, Junho 1996.

[10] S.-M. Yang and C.-H. Lee. A deadbeat current controller for field oriented induction motor drives. IEEE Trans. on Power Electronics, 17(5):772-778, 2002.

[11] E. Cerruto, A. Consoli, A. Raciti, and A. Testa. Fuzzy adaptive vector control of induction motor drives. IEEE Trans. on Power Electronics, 12(6):1028-1040, 1997.

[12] L. Harnefors and H.-P. Nee. Model-based current control of ac machines using the internal model control method. IEEE Trans. Ind. Applications, 34(1):10281040, January-February 1998.

[13] R. Kennel and A. Linder. Model predictive control for electrical drives. Power Electronics Specialists Conference-PESC, 13(4):1793-1799, 2005.

[14] I. Takahashi and T. Noguchi. A new quick-response and high-efficiency control strategy of an induction motor. IEEE Trans. Ind. Applications, IA-22(5):820-827, September-october 1986.

[15] M. Depenbrock. Direct self-control (dsc) of inverterfed induction machine. IEEE Trans. Power Electronics, 3(4):420-429, october 1988.

[16] J. H. Ryu, K. W. Lee, and J. S. Lee. A unified flux and torque control method for dtc-based induction-motor drives. IEEE Trans. on Power Electronics, 21(1):234242, January 2006.

[17] Y. Xue, X. Xu, T. G. Habetler, and D. M. Divan. A low cost stator flux oriented voltage source variable speed drive. Conference Record of the 1990 IEEE Industrial Aplications Society Annual Meetting, 1:410415, October 1990.

[18] D.M. Stojic and S. N. Vukosavic. A new induction motor drive based on the flux vector acceleration method. IEEE Trans. Ind. Applications, 20(1):173-180, March 2005.

[19] J. Maes and J. Melkebeek. Discrete direct torque control of induction motors using back emf measurements. IEEE IAS Annual Meeting, 1:407-414, 1998.

[20] J. H. Lee, C. G. Kim, and M. J.Youn. A deadbeat type digital controller for the direct torque control of an induction motor. IEEE Trans. on Power Electronics, 17:739-746, September 2002.

[21] C. Lascu, I. Boldea, and F. Blaabjerg. Direct torque control of sensorless induction motor drives: a sliding mode approach. IEEE Transactions on Industry Applications, 40(2):582-590, 2004.

[22] M. V. Lazarini and E. Ruppert Filho. Induction motor control didactic set-up using sensorless and sliding mode dtc strategy. Eletrônica de Potência, 13(4):291-299, Novembro 2008.

[23] P. Correa, M. Pacas, and J. Rodríguez. Predictive torque control for inverter-fed induction machines. IEEE Trans. on Power Electronics, 54(2):1073-1079, 2007.

[24] P. Z. Grabowski, M. P. Kazmierkowski, B. K. Bose, and F. Blaabjerg. A simple direct-torque neuro-fuzzy control of pwm-inverter-fed induction motor drive. IEEE Trans. Ind. Electronics, 47(1):863-870, 2000.

[25] M. Schroedl. Sensorless control of ac machines at low speed and standstill basedon the inform method. IEEE Industry Applications Conference, 1:270-277, October 1996.

[26] H. Kubota, I. Sato, Y. Tamura, K. Matsuse, H. Ohta, and Y. Hori. Regenerating-mode low-speed operation of sensorless induction motor drive with adaptive observer. IEEE Transactions on Industry Applications, 38(4):1081-1086, July-August 2002.

[27] B. H. Kenny and R. D. Lorenz. Stator and rotor flux based deadbeat direct torque control ofinduction machines. IEEE Industry Applications Conference, 1:133-139, Oct.-Nov. 2001.

[28] D. Casadei, G. Serra, and A. Tani. Steady-state and transient performance evaluation of a dtc scheme in the low speed range. IEEE Trans. on Power Electronics, 16(6):846-851, November 2001.

[29] W. Leonhard. Control of Electrical Drives. SpringerVerlag Berlin Heidelberg New York Tokyo, 1985.

[30] A. J. Sguarezi Filho. O controlador complexo aplicado ao controle vetorial do motor de indução. Mastert's thesis, FEEC-Unicamp, 2007.

[31] H. Tajima and K. Hori. Speed sensorless field orientation control of the induction machine. IEEE Industry Applications Society Annual Meeting, 1:385-391, 1991.

[32] J. Hu and B. Wu. New integration algorithms for estimating motor flux over wide speed range. IEEE Trans. on Power Electronics, 13(5):969-977, September 1998.

[33] C. Phillips. Feedback Control Systems. Pretince Hall, 2000.

[34] K. Ogata. Engenharia de Controle Moderno. LTC, 2000.

[35] G. Buja and R. Menis. Steady-state performance degradation of a dtc im drive under parameter and transduction errors. IEEE Transactions on Industrial Electronics, 55(4):1749-1760, 2008.

\section{BIOGRAPHIES}

Alfeu J. Sguarezi Filho received his bachelor degree on Electrical Engineering from Faculdade Area 1 and his Master degrees from Campinas University in Brazil, respectively in 2005 and 2007. He is working now toward the $\mathrm{PhD}$ degree at Campinas University. His research interests are electrical machines drive, electrical power systems, power control and doubly-fed induction generator for disperse generation use. Mr. Sguarezi is SOBRAEP member since June 2007.

Ernesto Ruppert Filho received his bachelor degree in Electrical Engineering and his Master and PhD degrees from Campinas University in Brazil, respectively in 1971, 1974 and 1983. From 1972 to 1978 he had been working at Electrical and Computer Enginneering School of Campinas University as an Assistance Professor in the Electromechanical Energy Conversion area, from 1979 to 1983 he had been working for General Electric in Brazil designing large induction and synchronous motors and working as an Application Engineer dedicated to large motors and generators, from 1983 to 1989 he had been working for Vigesa Heavy Equipments in Brazil designig very large hydrogenerators and also performing commissionig testes in some hydro power plants in Brazil. 
From 1989 to 1992 he runned his own company dealing with electrical installations and from 1992 up to now he is working as Full Professor at the Electrical and Computer Engineering School of Campinas University, in Campinas, Brazil, researching and teaching in the areas of Electrical Machines, Power Electronics, Drives and Electrical Power Systems. 